\title{
Impact of a Baby-Friendly hospital on breastfeeding indicators in Shaqlawa district in Erbil governorate, Kurdistan region of Iraq
}

\author{
N.Z. Shaker, ${ }^{7}$ S.S. Hasan ${ }^{1}$ and Z.A. Ismail ${ }^{1}$
}

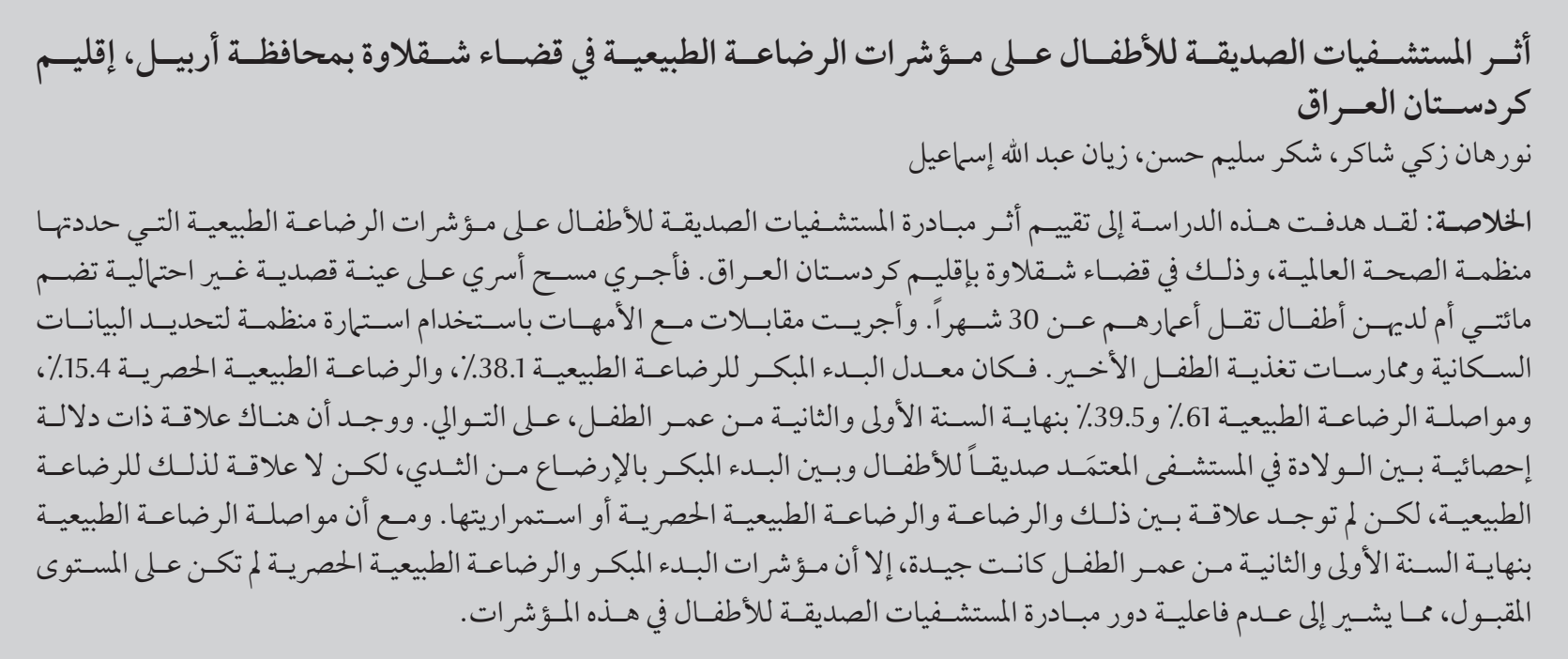

ABSTRACT This study aimed to assess the impact of the Baby-Friendly Hospital Initiative on WHO-defined breastfeeding indicators in Shaqlawa district in Kurdistan region of Iraq. A household survey was carried out on a purposive non-probability sample of 200 mothers with a child aged $<30$ months. Mothers were interviewed using a structured form to determine demographic data and feeding practices of the most recent child. The rate of early initiation of breastfeeding was 38.1\%, exclusive breastfeeding was $15.4 \%$ and continued breastfeeding was $61.0 \%$ and $39.5 \%$ at 1 and 2 years of age respectively. A significant relationship was found between delivery at the BabyFriendly accredited hospital and early initiation of breastfeeding but not with exclusive or continued breastfeeding. While continued breastfeeding at 1 year and 2 year was good, early initiation and exclusive breastfeeding indicators were not at an acceptable level, which indicates an ineffective role for the Baby-Friendly Hospital Initiative.

Impact d'un hôpital " ami des bébés » sur les indicateurs de l'allaitement dans le district de Shaqlawa du gouvernorat d'Erbil, Région du Kurdistan (Iraq)

RÉSUMÉ La présente étude visait à évaluer l'impact de l'initiative des hôpitaux « amis des bébés » sur les indicateurs de l'allaitement définis par l'Organisation mondiale de la Santé dans le district de Shaqlawa, Région du Kurdistan en Iraq. Une enquête auprès des ménages a été menée sur un échantillon non probabiliste choisi à dessein de 200 mères ayant un enfant âgé de moins de 30 mois. Les mères ont été interrogées à l'aide d'un formulaire structuré pour connaître leurs données démographiques et leurs pratiques d'allaitement concernant leur plus jeune enfant. Le taux d'instauration précoce de l'allaitement était de 38,1\%, d'allaitement exclusif au sein de 15,4 \% et de poursuite de l'allaitement à l'âge d'un an et de deux ans de 61,0 \% et 39,5\% respectivement. Un lien important a été observé entre un accouchement dans un hôpital accrédité " ami des bébés » et une instauration précoce de l'allaitement, mais aucun lien n'a été observé avec l'allaitement exclusif au sein ou la poursuite de l'allaitement. Si le taux de poursuite de l'allaitement jusqu'à un an et deux ans était satisfaisant, en revanche le niveau des indicateurs pour l'instauration précoce de l'allaitement et l'allaitement exclusif au sein était insuffisant, révélant le rôle inefficace de l'initiative des hôpitaux « amis des bébés». 


\section{Introduction}

Breastfeeding is an unequalled way of providing the ideal food for the healthy growth and development of infants, and is an integral part of the reproductive process with important implications for the health of the mother and child. Breastfeeding offers significant protection against illness for the infant, and numerous health benefits for the mother, including a decreased risk of breast cancer. If every baby were exclusively breastfed from birth to 6 months and breastfeeding were continued for a few months thereafter, an estimated 1.5 million lives would be saved each year (1). Yet barely 1 in 3 infants is exclusively breastfed during the first 6 months of life (2).

In view of the undeniable health benefits that breastfeeding offers to both women and children and the worrisome trends toward the decline in this behaviour, the United Nations Children's Fund (UNICEF) and World Health Organization (WHO) launched the Baby-Friendly Hospital Initiative (BFHI) in 1991, which aimed to increase rates of breastfeeding. "BabyFriendly" is a designation a maternity site can receive by demonstrating to external assessors' compliance with the Ten Steps to Successful Breastfeeding $(3,4)$.

On 24 January 2008 Shaqlawa general hospital in Erbil city of Kurdistan region was certified as a Baby-Friendly hospital by the Iraqi Ministry of Health and UNICEF as a preliminary step to promote, protect and support successful breastfeeding in the region. According to the head of the maternal and child health department of the Directorate of General Health in Erbil all Shaqlawa hospital staff initially participated in 3 training courses of 20 hours followed by many strengthening courses (S. Khalid, personal communication, 11 June 2015). Furthermore, this programme has received annual internal assessments by the hospital and frequent external assessments by the health administration of Kurdistan region and in July 2009 by the Iraqi Ministry of Health.

Unfortunately, compliance with breastfeeding recommendations in developing countries is low, and it has been suggested that more attention should be given to increasing breastfeeding rates and to monitoring trends $(1-5)$. The WHO indicators for assessing breastfeeding practices can be used to assess infant feeding within and across countries to evaluate the progress of breastfeeding promotion efforts. These indicators were generated using data from children aged under 24 months. The 3 core indicators and 2 optional indicators for breastfeeding are: early initiation of breastfeeding (proportion of children born in the last 24 months who are put to the breast within 1 hour of birth); exclusive breastfeeding under 6 months (proportion of infants $0-5$ months of age who are fed exclusively with breast milk); continued breastfeeding at 1 year (proportion of children 12-15 months of age who are fed breast milk); children ever breastfed (proportion of children born in the last 24 months who were ever breastfed); continued breastfeeding at 2 years (proportion of children 20-23 months of age who are fed breast milk) (1).

It is important to assess these indicators and the various determinants of breastfeeding in order to support successful interventions in the integrated health-care system towards giving the optimal practical support to mothers. To evaluate the impact of the BFHI in Shaqlawa district a study was designed to assess mothers' breastfeeding practices through calculation of core indicators.

\section{Methods}

\section{Study setting}

A household survey was conducted during October 2013. The study was carried out in the urban area of Shaqlawa district in Erbil governorate of the Kurdistan region of Iraq. The district of Shaqlawa lies $50 \mathrm{~km}$ north of Erbil city.

\section{Sample}

The sample size was determined according to the formula for margin of error: $n$ $=\left(z_{\alpha / 2} \sigma / E\right)^{2}$, where $z_{\alpha / 2}$ is the critical value, $\sigma$ is the standard deviation and $E$ is the margin of error. The sampling process was accomplished in 2 stages. In the first stage 8 neighbourhoods were selected randomly according to geographic areas from the list of 18 neighbourhoods of Shaqlawa district. In the second stage the random walk and quota sampling technique was used to select 25 households from each of the 8 neighbourhoods. Each household along the path was screened to ascertain the presence of mothers having a child aged less than 30 months, until the sample size of 200 mother-child pairs was reached (6).

\section{Tool}

A2-part structured form for interviewing mothers was developed by the researchers. The first section of the questionnaire collected data on demographic variables (mother's age and occupation, child's age and sex); type of delivery (vaginal, caesarean section) and place of delivery (Shaqlawa Baby-Friendly hospital, non-Baby-Friendly hospital, home). The second section assessed mothers' infant feeding practices, based on WHO breastfeeding indicators (including items about early initiation, exclusivity and duration of breastfeeding). The reliability of the questionnaire was determined via test-retest reliability. The Pearson correlation coefficient for reliability was good $(r=0.8)$.

WHO definitions of breastfeeding indicators were used: early initiation of breastfeeding (proportion of children born in the last 24 months who were put to the breast within 1 hour of birth); exclusive breastfeeding under 6 months (proportion of infants $0-5$ months of 
age who are fed exclusively with breast milk); continuing breastfeeding at the first year (proportion of children 12-15 months of age who are fed breast milk); continued breastfeeding rate over 2 years (proportion of children 20-23 months of age who are breastfeeding); and children ever breastfed (proportion of children born in the last 24 months who were ever breastfed) (7).

\section{Data collection}

Before data collection ethical approval was obtained from the ethics committee at College of Nursing, Hawler Medical University. Each mother's oral agreement for participation in the study was obtained after an explanation of the purpose of the study and guarantees of confidentiality and anonymity by the researchers. Data were collected using face-to-face interviews with mothers in their households. Three Kurdishspeaking researchers participated in the data collection which took 6 days.

\section{Data processing and analysis}

Data entry, processing and statistical analysis were carried out using SPSS, version 18. For demographic characteristics, frequency tables were carried out. Breastfeeding indicators were calculated according to equations established by WHO (1), and chi-squared for tests of significance were used to compare different groups and analyse the association between place of delivery and breastfeeding indicators. A $P$-value $\leq$ 0.05 was considered as statistically significant.

\section{Results}

\section{Sample profile}

From the urban area of Shaqlawa district 202 households were initially recruited for data collection and only 2 mothers refused participation in the study. Table 1 shows the demographic and birth data of the 200 mothers who participated. The mean

\begin{tabular}{lcc}
\hline \multicolumn{2}{l}{ Table 1 Demographic information of the studied } & mother-child pairs $(\boldsymbol{n}=\mathbf{2 0 0})$ \\
\hline Item & No. & $\%$ \\
Mother's age (years) & 2 & 1.0 \\
$\quad<18$ & 51 & 25.5 \\
$18-24.9$ & 92 & 46.0 \\
$25-31.9$ & 39 & 19.5 \\
$32-38.9$ & 16 & 8.0 \\
$39-45$ & & \\
Mother's occupation & 47 & 23.5 \\
$\quad$ Employed & 153 & 76.5 \\
$\quad$ Unemployed & & \\
Child's sex & 106 & 53.0 \\
$\quad$ Male & 94 & 47.0 \\
$\quad$ Female & & 18.0 \\
Type of delivery & 36 & 82.0 \\
Caesarean section & 164 & 3.5 \\
$\quad$ Normal vaginal delivery & & 28.0 \\
Place of delivery & 7 & 68.5 \\
$\quad$ Home & 56 & \\
Non-Baby-Friendly hospital & 137 & \\
$\quad$ Shaqlawa Baby-Friendly hospital & & \\
\hline
\end{tabular}

and standard deviation (SD) age of mothers was 28.7 (SD 5.1) years. Their mean years of formal education were 5.7 (SD 4.3) and $76.5 \%$ of mothers were unemployed. A great majority of mothers $(82.0 \%)$ gave birth to their most recent baby by normal vaginal delivery. Concerning the demographic characteristics of the studied children $52.5 \%$ were males

(Table 1), their mean age was 11.9 (SD 7.9) months and $24.0 \%$ were aged 18-23.9 months old (Figure 1).

\section{Breastfeeding indicators}

The study found that among all the mothers the rate of early initiation of breastfeeding was $38.1 \%$ and of exclusive breastfeeding was $15.4 \%$. The rates of continued breastfeeding of infants

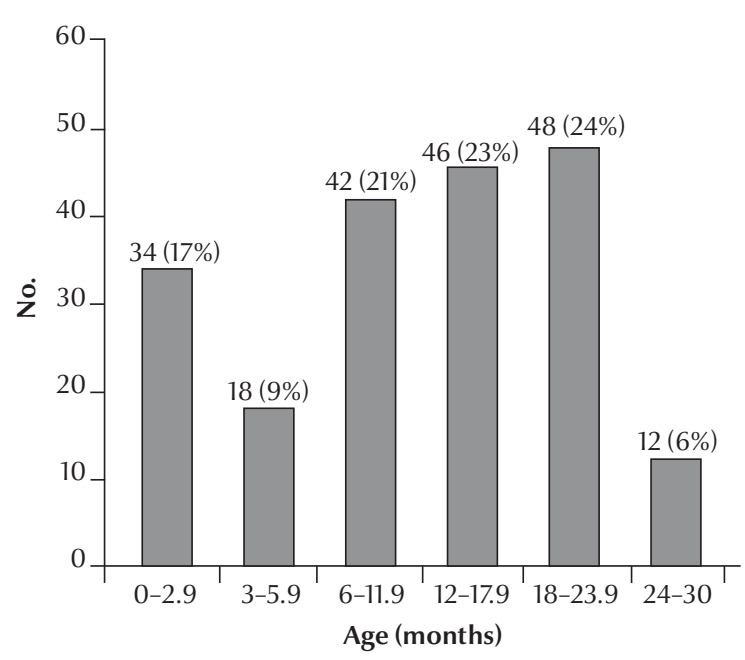

Figure 1 Distribution of the studied children by age $(n=200)$ 
at 1 and 2 years of age were $61.0 \%$ and $39.5 \%$ respectively. The rate of ever breastfeeding their most recent child was $98.0 \%$ and of never breastfeeding the child was $2.0 \%$ (Table 2).

\section{Breastfeeding indicators by type of hospital}

A total of 137 (68.5\%) of the mothers delivered their most recent child in Shaqlawa Baby-Friendly hospital and $56(28.0 \%)$ in non-Baby-Friendly hospitals, while 7 (3.5\%) mothers delivered at home (Table 1). When we analysed the breastfeeding indicators by type of hospital the results showed a highly significant relationship between place of delivery and the early initiation of breastfeeding but not with exclusive or continued breastfeeding (Table 3). Of the mothers who had delivered their child in Shaqlawa Baby-Friendly hospital $44.5 \%$ had initiated breastfeeding early during the first hour after delivery compared with only $17.9 \%$ of mothers who delivered in nonBaby-Friendly hospitals and $42.9 \%$ who delivered at home $(P=0.007)$. In contrast, $11.4 \%$ of infants delivered in Shaqlawa hospital (0-5.9 months of age) were on exclusive breastfeeding during the first 6 months of the infant's life compared with $25.0 \%$ delivered at non-Baby-Friendly hospitals $(P=0.363)$. The rate of continued breastfeeding was $53.3 \%$ of children delivered in Shaqlawa hospital and $50.0 \%$ delivered in non-Baby-Friendly hospitals $(P=0.296)$.

\section{Breastfeeding information to mothers at Shaqlawa hospital}

The results showed that $59.9 \%$ of mothers who delivered their children in Shaqlawa hospital received breastfeeding information during pregnancy in the primary health-care centre, $68.0 \%$ received breastfeeding information in the hospital after delivering the baby and $67.2 \%$ of them received breastfeeding information when visiting the primary health-care centre for newborn vaccination (Table 4). The researchers also found that there was no mothers' support groups in this hospital and the mothers had not received any gifts from formula milk companies.

\section{Discussion}

The Ministry of Health in the Iraqi Kurdistan region has adopted a policy in line with WHO/UNICEF for protection, promotion and support of breastfeeding. Shaqlawa district was selected for the application of this policy and the current study was carried out to determine the breastfeeding indicators of mothers in Shaqlawa. The study was well-received by households, and mothers were eager to participate. Step 4 of the WHO/UNICEF Ten Steps to Successful Breastfeeding recommends early initiation of breastfeeding. The BFHI assessment tool suggests that the baby should be placed "skin-to-skin" with the mother within the first half hour following delivery. In the current study, the rate of early initiation of breastfeeding was fair (38.1\%), comparable with the $\mathrm{WHO}$ rating (6). It is in agreement with the findings of a multiple indicator cluster survey in 2006 that indicated that only $31 \%$ of mothers in Iraq started breastfeeding within the first hour of birth (7). Another study in Erbil city showed that $24.3 \%$ of mothers were early initiators of breastfeeding (8). In contrast, early initiation of breastfeeding among Saudi Arabian mothers in 2008 was very high (95\%) (9).

Exclusive breastfeeding in the early months of life is correlated strongly with increased infant survival and lowered risk of illness, particularly gastritis (10). In the current study the rate of exclusive breastfeeding at $0-<6$ months was poor (15.4\%), which is comparable to the WHO rating (6). It is consistent with the multiple indicator cluster survey findings in 2011 but is higher than the exclusive breastfeeding rate in the earlier study in Erbil city (8.3\% of mothers) (8).

Although a high percentage of mothers in our survey received prenatal and postnatal education about breastfeeding, the rate of exclusive breastfeeding is not satisfactory. A Scottish study found that babies born in BFHI-accredited hospitals were $28 \%$ more likely to be exclusively breastfed at 7 days postpartum (11). In another randomized trial in Belarus, maternity hospitals were randomized to receive an intervention modelled on the BFHI or to continue with usual infant feeding

\begin{tabular}{lcccc}
\hline Table 2 Breastfeeding indicators among the studied & & & \\
\hline Indicator & $\begin{array}{c}\text { Relevant age } \\
\text { (months) }\end{array}$ & $\begin{array}{c}\text { Total no. of } \\
\text { children in this } \\
\text { age group }\end{array}$ & $\begin{array}{c}\text { No. of children } \\
\text { meeting } \\
\text { indicator }\end{array}$ & $\%$ \\
Early initiation of breastfeeding & $0-24$ & 194 & 74 & 38.1 \\
Exclusive breastfeeding for 6 months & $0-<6$ & 52 & 8 & 15.4 \\
Continued breastfeeding at 1 years & $12-<16$ & 36 & 22 & 61.0 \\
Continued breastfeeding at 2 years & $20-23$ & 43 & 17 & 39.5 \\
Ever breastfed & $0-30$ & 200 & 4 & 98.0 \\
Never breastfed & $0-30$ & 200 & 4 & 2.0 \\
\hline
\end{tabular}

Data refer to the most recent child. 


\begin{tabular}{|c|c|c|c|c|c|c|c|c|}
\hline \multirow[t]{3}{*}{ Breastfeeding indicator } & \multicolumn{6}{|c|}{ Place of delivery } & \multirow[t]{3}{*}{$x^{2}$-value } & \multirow[t]{3}{*}{$P$-value } \\
\hline & \multicolumn{2}{|c|}{ Home } & \multicolumn{2}{|c|}{$\begin{array}{c}\text { Non-Baby-Friendly } \\
\text { hospital }\end{array}$} & \multicolumn{2}{|c|}{$\begin{array}{l}\text { Shaqlawa Baby- } \\
\text { Friendly hospital }\end{array}$} & & \\
\hline & No. & $\%$ & No. & $\%$ & No. & $\%$ & & \\
\hline \multicolumn{9}{|c|}{ Early initiation of breastfeeding } \\
\hline No & 4 & 57.1 & 45 & 80.4 & 73 & 53.3 & 7.285 & 0.007 \\
\hline Yes & 3 & 42.9 & 10 & 17.9 & 61 & 44.5 & & \\
\hline Never breastfed & 0 & 0.0 & 1 & 1.8 & 3 & 2.2 & & \\
\hline \multicolumn{9}{|c|}{ Exclusive breastfeeding (0-5.9 months) } \\
\hline No & 1 & 0.5 & 12 & 75.0 & 31 & 88.6 & 0.829 & 0.363 \\
\hline Yes & 0 & 0.0 & 4 & 25.0 & 4 & 11.4 & & \\
\hline \multicolumn{9}{|c|}{ Continued on breastfeeding } \\
\hline No & 5 & 71.4 & 28 & 50.0 & 64 & 46.7 & -0.074 & 0.296 \\
\hline Yes & 2 & 28.6 & 28 & 50.0 & 73 & 53.3 & & \\
\hline
\end{tabular}

practices and policies. The study found an increase in the duration and exclusivity of breastfeeding associated with BFHI hospitals, as well as a decreased incidence of gastrointestinal disease and atopic eczema during the first year of life (12).

The Innocent Declaration adopted by participants at the WHO/UNICEF Policy Makers Meeting on Breastfeeding in the early 1990s recommended that babies continue to be breastfed for up to 2 years of age or beyond. When provided along with appropriate and adequate complementary food, breast milk continues to be an important source of nutrition and fluids and immunological protection for the child after 6 months of age. The continued bonding between mother and child provided by breastfeeding encourages optimal psychosocial development (6).
The current study in Erbil district found that the rate of continuing breastfeeding in year 1 by all the mothers in the sample was $61.0 \%$. This is much lower than in the study from Oman, in which $95 \%$ of mothers continued breastfeeding their infants at the age of 1 year (13), and in another study from Erbil city (70.1\%) (10). The rate of continued breastfeeding at 2 years in our study was $39.5 \%$ and this is slightly higher than what was previously found in Erbil city (33.3\%) (10). It is much lower, however, than the rate reported from studies conducted in Qatar (45.4\%) (5) and in the Islamic Republic of Iran (57\%) (14).

The proportion of children ever breastfed, as an optional indicator, was $98.0 \%$, indicating that most mothers in Shaqlawa district practised breastfeeding at some time before the child was 2 years of age, even if not for sufficiently long periods. This figure is consistent with results reported at the national level in Qatar (97.9\%) (5) and Egypt (95.8\%) (13).

The setting in which a woman gives birth can have an impact on her breastfeeding outcomes. The current study found that early initiation of breastfeeding was significantly associated with place of delivery (44.5\% in Shaqlawa Baby-Friendly accredited hospital versus only $17.9 \%$ in non-Baby-Friendly hospitals). This finding is consistent with a retrospective cohort study in the United States of America which explored the impact of variations in practice at different hospitals as a component of breastfeeding outcomes $(15,16)$. In contrast, our study found no significant association between place of delivery and exclusive or continued breastfeeding indicators. We interpret this to ineffective

\begin{tabular}{|c|c|c|c|c|}
\hline \multicolumn{5}{|l|}{$\begin{array}{l}\text { Table } 4 \text { Receipt of information about breast } \\
\text { Shaqlawa Baby-Friendly hospital }(n=137)\end{array}$} \\
\hline \multirow[t]{2}{*}{ Breastfeeding information } & \multicolumn{2}{|c|}{ Yes } & \multicolumn{2}{|c|}{ No } \\
\hline & No. & $\%$ & No. & $\%$ \\
\hline $\begin{array}{l}\text { Mother received information on breastfeeding during pregnancy in primary health- } \\
\text { care centre }\end{array}$ & 82 & 59.9 & 55 & 40.1 \\
\hline $\begin{array}{l}\text { Mother received information on initiation and exclusive breastfeeding after } \\
\text { delivering baby in Shaqlawa hospital }\end{array}$ & 93 & 67.9 & 44 & 32.1 \\
\hline $\begin{array}{l}\text { Mother received information on breastfeeding when visiting primary health-care } \\
\text { centre for newborn vaccination }\end{array}$ & 92 & 67.2 & 45 & 32.8 \\
\hline
\end{tabular}


breastfeeding education by health workers in Baby-Friendly hospitals and to a lack of follow-up of mothers at home for continuation of breastfeeding. Although there is an internal assessment annually among Shaqlawa hospital staff, the present adverse conditions in the Kurdistan region of Iraq mean that since 2014 not all the criteria are being met. Limited financial support and the heavy workload on health professionals due to the large number of refugees from the Syrian Arab Republic and other parts of Iraq who need urgent health care is likely to have a negative influence on breastfeeding indicators.
The findings of the current study are subject to certain limitations. The data were dependent on mothers' 24-hour recall, which can give a false picture of breastfeeding practices as these may change daily. However, this is the approach adopted by the $\mathrm{WHO}$ as the standard for assessment of breastfeeding indicators.

\section{Conclusion and Recommendations}

The current steps in BFHI designations used by the Ministry of Health in the
Iraqi Kurdistan region needs verification to reach the necessary standards to attain the global criteria for BabyFriendly hospitals. We recommend that the current process of Baby-Friendly in Shaqlawa hospital needs revitalization and improvement to follow the Ten Steps of Successful Breastfeeding and the programme should be extended by the Ministry of Health in the Iraqi Kurdistan region. Further studies are need to understand the obstacles to choosing early initiation and exclusive breastfeeding by mothers.

\section{Funding: None.}

Competing interests: None declared.

\section{References}

1. Indicators for assessing infant and young child feeding practices: conclusions of a consensus meeting held 6-8 November 2007 in Washington D.C., USA. Geneva: World Health Organization; 2007 (http://apps.who.int/iris/bitstre am/10665/43895/1/9789241596664_eng.pdf, accessed 10 November 2015).

2. Optimal duration of exclusive breastfeeding: a systematic review. Geneva: World Health Organization; 2008 (WHO/ $\mathrm{NHD} / 01.08 \mathrm{WHO} / \mathrm{FCH} / \mathrm{CAH} / 01.23$ ) (http://apps.who.int/ iris/bitstream/10665/67208/1/WHO_NHD_01.08.pdf, accessed 10 November 2015).

3. Philipp BL, Radford A. Baby-Friendly: snappy slogan or standard of care? Arch Dis Child Fetal Neonatal Ed. 2006 Mar;91(2):F145-9. 10.1136/adc.2005.074443 PMID:16492953

4. Pérez-Escamilla R. Evidence based breast-feeding promotion: the Baby-Friendly Hospital Initiative. J Nutr. 2007 Feb;137(2):484-7. PMID:17237332

5. Al-Kohji S, Said HA, Selim NA. Breastfeeding practice and determinants among Arab mothers in Qatar. Saudi Med J. 2012 Apr;33(4):436-43.www.smj.org.sa PMID:22485241

6. Infant and young child feeding: a tool for assessing national practices, policies and programmes. Geneva: World Health Organization; 2003 (http://www.who.int/nutrition/publications/inf_assess_nnpp_eng.pdf, accessed 10 November 2015).

7. Iraq multiple indicator cluster survey 2006. Monitoring the situation of children and women, Volume 1: final report. Geneva: United Nations Children's Fund; 2007 (http://www. childinfo.org/files/MICS3_Iraq_FinalReport_2006_eng.pdf, accessed 10 November 2015).

8. Al-Azzawi SI, Hussein KA, Shaker NZ. Knowledge, attitude and practices (KAP) of mothers toward infant and young child feed- ing in primary health care $(\mathrm{PHC})$ canters. Erbil city. Kufa Journal for Nursing Sciences. 2012;2(2):1-10.

9. Al-Hreashy FA, Tamim HM, Al-Baz N, Al-Kharji NH, Al-Amer $\mathrm{A}, \mathrm{Al}$-Ajmi $\mathrm{H}$, et al. Patterns of breastfeeding practice during the first 6 months of life in Saudi Arabia. Saudi Med J. 2008 Mar;29(3):427-31. PMID:18327373

10. Iraq multiple indicator cluster survey 2011. Preliminary report April 2012. Geneva: United Nation's Children's Fund (http:// www.childinfo.org/files/MICS4_Iraq_PreliminaryReport_Eng. pdf, accessed 10 November 2015).

11. Broadfoot M, Britten J, Tappin DM, MacKenzie JM. The Baby Friendly Hospital Initiative and breast feeding rates in Scotland. Arch Dis Child Fetal Neonatal Ed. 2005 Mar;90(2):F114-6. PMID:15724033

12. Kramer MS, Chalmers B, Hodnett ED, Sevkovskaya Z, Dzikovich I, Shapiro S, et al.; PROBIT Study Group (Promotion of Breastfeeding Intervention Trial). Promotion of breastfeeding intervention trial (PROBIT): a randomized trial in the Republic of Belarus. JAMA. 2001 Jan 24-31;285(4):413-20. PMID:11242425

13. WHO global data bank on infant and young child feeding (IYCF) [Internet]. Geneva: World Health Organization; 2010 (http://www.who.int/nutrition/databases/infantfeeding/ countries/en, accessed 10 November 2015).

14. Olang B, Farivar K, Heidarzadeh A, Strandvik B, Yngve A. Breastfeeding in Iran: prevalence, duration and current recommendations. Int Breastfeed J. 2009;4:8. PMID:19656361

15. Kruse L, Denk CE, Feldman-Winter L, Rotondo FM. Comparing sociodemographic and hospital influences on breastfeeding initiation. Birth. 2005 Jun;32(2):81-5. PMID:15918863

16. Forster DA, McLachlan HL. Breastfeeding initiation and birth setting practices: a review of the literature. J Midwifery Womens Health. 2007 May-Jun;52(3):273-80. PMID:17467594 